\title{
OS LUGARES E O NOME (A CONFIGURAÇÃO DO ESPAÇO SERTANEJO NO ROMANTISMO) ${ }^{1}$
}

\author{
Eduardo Vieira Martins \\ Universidade Estadual de Campinas
}

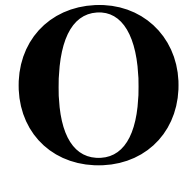

leitor que percorrer os romances românticos voltados para a representação da vida no interior do país talvez se sinta desconcertado diante da variedade de lugares neles catalogados sob a rubrica de "sertão". O objetivo deste artigo é, a partir da leitura de alguns textos - em especial do romance $O$ sertanejo, de José de Alencar -, discutir o significado que essa palavra possuía no período.

Nome dado a um território de contornos incertos e delimitação convencional, o termo "sertão" possuía, no século XIX, um sentido um pouco diferente do atual, sendo usado para designar regiões consideradas hoje externas a esse espaço. Uma consulta aos dicionários revela que em nossos dias a palavra designa, principalmente, as porções áridas do interior dos estados do Norte e Nordeste, incluindo também áreas do norte de Minas Gerais e algumas regiões de Goiás e Tocantins. Câmara Cascudo, advertindo que "as tentativas para caracterizá-lo têm sido mais convencionais que reais", descreve-o, inicialmente, como "o interior" do país, de forma genérica, mas a seguir observa que "o nome fixou-se no Nordeste e Norte, muito mais do que no sul. O interior do Rio

${ }^{1}$ Este artigo foi elaborado a partir da minha dissertação de mestrado, intitulada A imagem do sertão em José de Alencar, desenvolvida no Instituto de Estudos da Linguagem (IEL) da Unicamp, sob orientação do Prof. Dr. Luiz Dantas. 
Grande do Sul não é sertão, mas poder-se-ia dizer que sertão era o interior de Goiás e Mato Grosso, na fórmula portuguesa do século XIX".2 Aurélio Buarque de Holanda define-o como uma "região agreste, distante das povoações ou terras cultivadas", como "terreno coberto de mato, longe do litoral". O sertão seria a "zona pouco povoada do interior do país, em especial do interior semi-árido da parte norte-ocidental". ${ }^{3}$ Para Walnice Nogueira Galvão, por fim, "dáse o nome de sertão a uma vasta e indefinida área do interior do Brasil, que abrange boa parte dos estados de Minas Gerais, Bahia, Sergipe, Alagoas, Paraíba, Pernambuco, Rio Grande do Norte, Ceará, Piauí, Maranhão, Goiás e Mato Grosso. É o núcleo central do país". ${ }^{4}$

No século XIX, essa limitação territorial ainda não havia ocorrido. Antonio de Morais Silva - considerado por José de Alencar como "o primeiro lexicólogo da língua" -, mantém o verbete "sertão" praticamente inalterado na primeira e na segunda edições de seu prestigioso dicionário. Na primeira, de 1789, o termo era definido como "o interior, o coração das terras, opõe-se ao marítimo, e costa, longe da costa". ${ }^{6} \mathrm{Na}$ segunda, de 1813, que segundo Wilson Martins era tida como "a boa", 7 Morais mantém a mesma definição, acrescentando e modificando exemplos do uso da palavra: "[...] v.g.

${ }^{2}$ CASCUDO, Luís da Câmara. Dicionário do folclore brasileiro. Rio de JaneirO, INL, 1954.

${ }^{3}$ FERREIRA, Aurélio Buarque de Holanda. Novo dicionário da língua portuguesa. Ed. Nova Fronteira, s.d.

${ }^{4}$ GALVÃO Walnice Nogueira. As formas do falso. Ed. Perspectiva, 1986. p. 25.

${ }^{5}$ ALENCAR, José de. O nosso cancioneiro. In: Ficção completa e outros escritos. v. 4.Rio de Janeiro, Ed. José Aguilar, 1960. p.968.

${ }^{6}$ SILVA, Antonio de Morais. Dicionário da lingua portuguesa. Composto pelo Pe. D. Rafael Bluteau, reformado e acrescentado por Antonio de Morais Silva (natural do Rio de Janeiro). Lisboa, Oficina de Simão Thadeu Ferreira, 1789.

${ }^{7}$ MARTINS, Wilson. História da inteligência brasileira. v. 2. São Paulo, Ed. Cultrix, 1978. p. 45. 
'Cidade do sertão; mercadores do sertão.' [...] fig. 'Bem pelo sertão dentro de um pensamento.' [...] O sertão toma-se por mato longe da costa. [...]". ${ }^{8}$ Outros dicionaristas do século XIX atribuíam o mesmo sentido ao termo. Luiz Maria da Silva Pinto, por exemplo, no seu Dicionário da língua brasileira (1832), definia-o como "o interior das terras. Mato distante da costa marítima. 'Sertão da calma', o lugar onde ela é mais intensa". Eduardo de Faria (1859), numa tentativa de etimologia, explicava que a palavra tinha sua origem em "serra, e souto, mato", e designava "a região interior remota da costa do mar, mato interior". Em sentido figurado, a expressão "bem pelo sertão" indicava "no mais íntimo". ${ }^{10}$ Para o poeta e historiador inglês Robert Southey, que ao se referir a esse espaço no segundo volume da sua História do Brasil (1822) esclarece o sentido do termo, o sertão era "O interior do país". ${ }^{11}$

Podem-se encontrar exemplos dessa concepção mais ampla do espaço sertanejo em vários autores do período. Martins Pena, em O diletante (1844), referia-se à província de São Paulo como sertão; em O gaúcho (1870), de José de Alencar, os pampas do Rio Grande do Sul, ao contrário do que propõe Câmara Cascudo, eram chamados pelo mesmo nome $;^{12}$ e para o Visconde de Taunay, tanto o Mato Grosso, palco de Inocência (1872), quanto o Paraná, evocado

${ }^{8}$ SILVA, Antonio de Morais. Dicionário da língua portuguesa. Lisboa, 1813.

${ }^{9}$ PINTO, Luiz Maria da Silva. Dicionário da língua brasileira. Ouro Preto: Tipografia de Silva, 1832.

${ }^{10}$ FARIA, Eduardo de. Novo dicionário da língua portuguesa. Rio de Janeiro, 1859.

${ }^{11}$ SOUTHEY, Robert. History of Brazil. v. 2. New York, Lenox Hill Pub., 1970. p. 565: "This word requires explanation. Sertam, or Certam (as it is sometimes spelt), in the plural Sertoens, means the interior of the country. An inhabitant of the interior is called a Sertanejo. I do not know the origin of the word".

${ }^{12}$ Falando sobre Dom Romero, o narrador afirma que "o chileno tinha-se dirigido para aquele lado da província com intenção de percorrer as vilas e povoações do sertão até Cruz Alta". Ver ALENCAR, José de. O gaúcho e O tronco do ipê. Rio de Janeiro: José Olympio Ed., 1977. p.148. 
em Visões do sertão, faziam parte daquele espaço. O fato de regiões tão distantes e diferentes uma das outras serem designadas pelo mesmo nome dificulta a tarefa de determinar o elemento que, na concepção desses autores, o caracterizava e distinguia. Morais Silva descrevia-o como o interior, as áreas de mato distantes do litoral. Entretanto, não era qualquer região do interior que se considerava como sertão, e nem sempre era fácil saber o que fazia e o que não fazia parte dele.

No romance Til (1872), de José de Alencar, essa separação aparece com bastante clareza. Apesar de a fazenda das Palmas, cenário da ação, localizar-se no interior da província de São Paulo, ela foge aos domínios do sertão, o que se pode perceber quando o narrador afirma que "no inverno costumavam passar por aquelas paragens ranchos de caçadores que demandavam o sertão para a monteria das antas e veados que ainda abundavam nos campos de Araraquara e Botucatu"; ou então, que "um tigre que descera do sertão destruía o gado de uma fazenda próxima, cujo dono prometera boa recompensa a quem o matasse". ${ }^{13}$ O sertão não é aqui, ele está além, é o lugar para onde os viajantes se dirigem e de onde vem o tigre que ataca a fazenda. Ao relatar sua viagem pelo interior do Brasil, sir Richard Francis Burton deparou-se com o problema da delimitação do espaço sertanejo. Referindo-se à sua passagem pela cidade de Curvelo, o explorador inglês observa que ela

está construída no campo e é a última dessa região, sendo considerada como servindo de demarcação ao sertão ou região do extremo oeste. Os habitantes, contudo, nunca se mostram muito dispostos a se considerarem sertanejos; os viajantes estão sempre se aproximando do sertão e sempre descobrindo que ele ainda fica a alguns dias de viagem. Faz lembrar as terras dos "nyam-nyans" rabudos, que sempre fogem diante do explorador ou, em uma comparação mais modesta, os charcos de certos condados ingleses, que, de acordo com os pálidos

${ }^{13}$ ALENCAR, José de. Til. São Paulo, Ed. Melhoramentos, 1973. pp.89 e 121. 
informantes, atacados de febres palustres e de pés espalmados, não têm a honra de ser o lugar de sua residência. ${ }^{14}$

Semelhante atitude de repulsa também é registrada por Saint-Hilaire, que, ao narrar sua passagem por uma fazenda, refere-se ao relato de pessoas que "tinham a pretensão de achar que aquelas terras não faziam parte do sertão, o qual - afirmavam eles - só começava do outro lado de algumas montanhas situadas entre aquela região e o São Francisco". ${ }^{15}$

Sempre recuando diante dos passos do viajante que avançava em sua direção, o sertão impunha dificuldades àqueles que tentavam demarcar suas fronteiras. Saint-Hilaire, a certa altura da narrativa das suas Viagens pelas províncias de Rio de Janeiro e Minas Gerais (1830), procura determinar a localização do sertão dessa última província, o que o obriga, em primeiro lugar, a defini-lo e a tentar dissipar falsas idéias sobre ele. Para o viajante francês, "o nome Sertão ou Deserto não designa uma divisão política do território; não indica senão uma espécie de divisão vaga e convencional determinada pela natureza particular do território e, principalmente, pela escassez de população”. Numa nota explicativa, acrescenta que

várias províncias, e todas talvez, tenham seu sertão, que é a sua parte mais deserta. Os sertões de Minas, Bahia e Pernambuco são regiões descobertas, e o da Província de Espírito Santo apresenta densas florestas. Parece mesmo que uma única província pode ter vários sertões, pois que, além do de Bahia, vizinho do sertão de Minas, as florestas desertas que se estendem a oeste do litoral para o lado de Belmonte, são ainda um sertão. ${ }^{16}$

Há nessas observações um indício do traço distintivo utilizado pelo autor para definir as regiões que receberiam o nome de

${ }^{14}$ BURTON, Richard. Viagem de canoa do Sabará ao Oceano Atlântico. Edusp/ Ed. Itatiaia, 1977. p. 136.

${ }^{15}$ SAINT-HILAIRE, Auguste de. Viagem às nascentes do Rio São Francisco. Edusp/Itatiaia, 1975. p. 156.

${ }^{16}$ Idem. Viagens pelas províncias de Rio de Janeiro e Minas Gerais. Edusp/ Itatiaia, 1975. p. 307. 
"sertão". A imagem desse espaço ligava-se à de deserto, os dois termos eram usados como sinônimos ("Sertão ou Deserto", dizia Saint-Hilaire), e o segundo deles prendia-se mais à fraca densidade demográfica da região do que à sua aridez ou pobreza de vegetação. ${ }^{17}$ Assim, o nome podia ser atribuído tanto a uma região "descoberta" e árida, quanto a outra "coberta" por densa floresta: o que o definia não era o tipo de vegetação, clima ou terreno, como ocorre em nossos dias, mas a baixa densidade demográfica e a distância do litoral e dos núcleos de povoação. Dessa perspectiva, o Grand dictionaire universal du XIXe siécle (1875), definia-o como o "nome dado, no Brasil, a certas partes do território de qualquer província pouco povoada ou inculta". ${ }^{18}$ Spix e Martius registram sua entrada nesse espaço dizendo, "achamo-nos agora no sertão, como denominam os mineiros a vastidão deserta, na sua linguagem usual". ${ }^{19} \mathrm{O}$ mesmo Martius, no texto em que discutiu os rumos que deveria tomar a historiografia brasileira, observou que o estudioso encontraria "um atrativo variadíssimo na narração das numerosas viagens de descobertas e incursões dos diferentes pontos do litoral para os desertos longínquos do interior (os sertões), empreendidas

${ }^{17}$ Segundo alguns autores, a palavra "sertão" teria evoluído de "desertão". Ver Richard Burton, op. cit., p. 143, n 5: "Southey escreve a palavra de acordo com a moda antiga, sertam, e diz não saber sua origem. É apenas contração do aumentativo desertão, e muito usado na África e na América do Sul"; e Câmara Cascudo, op. cit., verbete sertão: "A origem ainda se discute e apareceu mesmo a idéia de forma contrata de desertão".

${ }^{18}$ LAROUSSE, Pierre. Grand dictionaire universel du XIXe siécle. Paris, 1875. "Sertao ou Sertam: nom donné, au Brésil, à certaines parties du territoire de quelques provinces peu peuplées ou incultes, entre autres aux solitudes du San-Francisco, dans la province de Minas-Geraes. Les rares habitantes qu'on recontre dans ce désert sont appelés Sertanejos."

${ }^{19}$ SPIX, Johann-Baptist von e MARTIUS, Carl Philipp von. Viagem pelo Brasil (1817-1820). v. 2. Edusp/Ed. Itatiaia, 1981. p.75.

${ }^{20}$ MARTIUS, Carl Philipp von. "Como se deve escrever a história do Brasil". In: O estado do direito entre os autóctones do Brasil. Edusp/Ed. Itatiaia, 1982. p.100. 
em procura de ouro e pedras preciosas, ou com o fim de cativar e levar como escravos os indígenas". ${ }^{20}$ Os sertões eram os desertos, os vazios, as regiões do interior afastadas das concentrações humanas, as áreas onde a natureza inculta ainda não havia sido dominada e transformada por vilas e cidades.

A percepção do sertão como um espaço pouco povoado - não necessariamente árido - levou a uma aproximação dos vocábulos "sertão", "deserto" e "floresta". Em O ermitão de Muquém (1858), por exemplo, Bernardo Guimarães usa as três palavras como sinônimos. Descrevendo a fuga de Gonçalo da cidade de Goiás, o narrador afirma que ele "foi-se entranhando de mais em mais pelos sertões" e, desesperado, "vagava a esmo pelos desertos". ${ }^{21}$ A índia Guaraciaba, que Gonçalo encontra na tribo dos Chavantes, é referida, ao mesmo tempo, como a "filha da floresta"22 e a "virgem do deserto". ${ }^{23}$ Em José de Alencar, Iracema é descrita ora como a "filha das florestas", ${ }^{24}$ ora como a "selvagem filha do sertão". ${ }^{25}$ Quando Martim se prepara para deixar o campo dos tabajaras, a índia o presenteia com sua rede, e o português lhe responde que essa rede será sua "companheira no deserto". ${ }^{26}$

A mesma identificação terminológica ocorre também em Inocência, romance que se inicia com uma cuidadosa descrição do espaço em que se irá desenvolver a história:

Corta extensa e quase despovoada zona da parte sul-oriental da vastíssima província de Mato-Grosso a estrada que da vila de Sant'Ana do Paranaíba vai ter ao sítio abandonado de Camapoan. Desde aquela

${ }^{21}$ GUIMARÃES, Bernardo. O ermitão de Muquém e O garimpeiro. Livraria Martins Ed., 1955. p. 89.

${ }^{22}$ Idem, p. 76.

${ }^{23}$ Idem, p. 89.

${ }^{24}$ ALENCAR, José de. Iracema. São Paulo, Edusp, 1979. p. 13.

${ }^{25}$ Idem, p. 20.

${ }^{26}$ Idem, p. 25. 
povoação, assente próximo ao vértice do ângulo em que confinam as muitas dezenas de léguas, anda-se comodamente, de habitação em habitação, mais ou menos chegadas umas às outras; rareiam, porém, depois as casas, mais e mais, e caminha-se largas horas, dias inteiros sem se ver morada nem gente até o retiro de João Pereira, guarda avançada daquelas solidões, homem chão e hospitaleiro, que acolhe com carinho o viajante desses alongados páramos, oferece-lhe momentâneo agasalho e o provê da matalotagem precisa para alcançar os campos de Miranda e Pequerí, ou da Vacaria e Nioac, no Baixo Paraguai. Ali começa o sertão chamado bruto.

Pousos sucedem a pousos, e nenhum teto habitado ou ruínas, nenhuma palhoça ou tapera dá abrigo ao caminhante contra a frialdade das noites, contra o temporal que ameaça, ou a chuva que está caindo. Por toda a parte, a calma da campina não arroteada; por toda a parte, a vegetação virgem, como quando aí surgiu pela vez primeira. ${ }^{27}$

Percorrendo a estrada que leva da "vila" ao "sítio abandonado", o viajante vê as casas e povoados espaçarem-se gradualmente. O "retiro de João Pereira" assinala sua entrada no sertão "bruto", expressão que, segundo o narrador, quer dizer "sem moradores", ${ }^{28}$ enquanto a vila de Sant'Ana do Paranaíba é descrita como o "ponto terminal do sertão", ${ }^{29}$ ou seja, o local onde a província torna-se mais habitada. Mesmo indicando-se no mapa seu início e fim, o caráter fugidio do território persiste, uma vez que essas balizas dependem unicamente da densidade demográfica. É de se notar que o retiro de João Pereira constitui um marco, não porque haja algum acidente geográfico notável nas suas imediações ou porque assinale a entrada num tipo definido de terreno ou vegetação, mas apenas pelo fato de, depois dele, as habitações tornarem-se ainda mais raras. Apesar da tentativa de se erigir pontos de referência claros, parece que o sertão escapa entre as mãos do narrador, que, ao referir-se ao "elemento dominante na composição de todo aquele solo", a areia,

${ }^{27}$ TAUNAY, Visconde de. Inocência. Rio de Janeiro, Ediouro, s.d. pp. 7-8.

${ }^{28}$ Idem, p. 8, nota 2.

${ }^{29}$ Idem, p. 167. 
acaba por usar uma expressão que apreende com bastante acuidade o caráter de que a imagem desse território vai se revestindo: "Em alguns pontos é tão fofa e movediça que os animais das tropas viageiras arquejam de cansaço, ao vencerem aquele terreno incerto, que lhes foge sob o casco e onde se enterram até meia canela". ${ }^{30} \mathrm{De}$ fato, o sertão tem algo de um "terreno incerto" e movediço, que não se pode definir com clareza, pois mal se escolhem algumas balizas para assinalar os seus domínios, elas se desfazem e ele foge diante dos olhos do observador.

Num texto intitulado "Cruzando o Sertão", no qual descreve sua volta ao Rio de Janeiro, depois de terminada a retirada da Laguna, Taunay utiliza outra expressão que sintetiza muito bem essas imagens. Relatando sua passagem por Sant'Ana do Paranaíba, afirma que a vila localiza-se "à entrada da região mais efetivamente habitada, uma vez atravessadas as vastas solidões interpostas". ${ }^{31} \mathrm{Em}$ Inocência, o ficcionista caracteriza o sertanejo como um "explorador de desertos", cujo "fim único é devassar terras, pisar campos onde ninguém antes pusera pé". ${ }^{32}$ Essa obsessão o levaria a abandonar sua casa e sair "por aí além", "uns nos confins do Paraná, outros nas brechas de São Paulo, nas planuras de Goiás ou nas bocainas de Mato Grosso, por toda parte enfim, onde haja deserto". ${ }^{33}$ Taunay, em consonância com a perspectiva de seu tempo, via o sertão como "as vastas solidões interpostas", a terra pouco povoada que se esgueirava entre as vilas e freguesias do interior do país.

É dentro desse mesmo campo de significação que Alencar compreende o sertão e elabora o cenário de O sertanejo (1875). Em sintonia com o cânon da ficção romântica, o romance inicia-se pela evocação do espaço onde a ação irá se desenvolver:

${ }^{30}$ Idem, p. 8.

${ }^{31}$ Idem. "Cruzando o Sertão". In: Visões do sertão. São Paulo, Of. Gráf. Monteiro Lobato \& R. Gusmão, 1923. p. 10.

${ }^{32}$ Idem. Inocência. Ed. cit. p. 15.

${ }^{33}$ Idem, p. 17. 
Esta imensa campina, que se dilata por horizontes infindos, é o sertão de minha terra natal.

Aí campeia o destemido vaqueiro cearense, que à unha de cavalo acoça o touro indômito no cerrado mais espesso, e o derriba pela cauda com admirável destreza.

Aí, ao morrer do dia, reboa entre os mugidos das reses, a voz saudosa e plangente do rapaz que abóia o gado para o recolher aos currais no tempo da ferra.

Quando te tornarei a ver, sertão da minha terra, que atravessei há tantos anos na aurora serena e feliz de minha infância?

Quando tornarei a respirar tuas auras impregnadas de perfumes agrestes, nas quais o homem comunga a seiva dessa natureza possante? De dia em dia aquelas remotas regiões vão perdendo a primitiva rudeza, que tamanho encanto lhes infundia.

A civilização que penetra pelo interior corta os campos de estradas, e semeia pelo vastíssimo deserto as casas e mais tarde as povoações.

Não era assim no fim do século passado, quando apenas se encontravam de longe em longe extensas fazendas, as quais ocupavam todo o espaço entre as raras freguesias espalhadas pelo interior da província. Então o viajante tinha de atravessar grandes distâncias sem encontrar habitação, que lhe servisse de pousada; por isso, a não ser algum afouto sertanejo à escoteira, era obrigado a munir-se de todas as provisões necessárias à comodidade como à segurança. ${ }^{34}$

Se por um lado essa apresentação assemelha-se às "cenas da natureza" com as quais se abriam muitos romances românticos, por outro, difere delas em pontos importantes, como, por exemplo, no fato de não indicar a localização do cenário evocado. Ao contrário de romances como O guarani, Inocência e O garimpeiro (de Bernardo Guimarães), que logo nas primeiras linhas situam o ponto do mapa onde a ação irá transcorrer, em O sertanejo as primeiras coordenadas geográficas são fornecidas apenas no décimo parágrafo, quando, terminada a evocação inicial do sertão, o narrador desvia os olhos dos "horizontes infindos" para focalizar

${ }^{34}$ ALENCAR, José de. O sertanejo. In: Ficção completa e outros escritos. v. 3. Rio de Janeiro, Cia. Aguilar Ed., 1965. p.527. 
uma caravana de viajantes, dando início à narrativa: "Assim fizera o dono do comboio que no dia 10 de dezembro de 1764 seguia pelas margens do Sitiá buscando as faldas da Serra de Santa Maria, no sertão de Quixeramobim". ${ }^{35}$ Antes de receber essas informações, o leitor sabe apenas que o espaço em questão não é um lugar qualquer, mas "o sertão de minha terra natal". A ligação afetiva que prende o narrador ao espaço faz com que a evocação do cenário seja banhada pela nostalgia, que contamina a narrativa e a descrição do sertão. Definida pelo romancista como o "marasmo da ausência", ${ }^{36}$ a nostalgia estaria presente no próprio nome "Quixeramobim", relacionado à saudade do passado. Em uma nota a Iracema, Alencar, citando o naturalista alemão Carl Philipp von Martius, afirma ser essa palavra uma "exclamação de saudade", composta por "Qui: ah!, xere: meus, amôbinhê: outros tempos". ${ }^{37}$ O sertão surge, assim, como um espaço ausente, perdido no passado, "na aurora serena e feliz de minha infância".

A evocação inicial do sertão de Quixeramobim também diverge daquele modelo romântico de abertura por relegar o aspecto descritivo a um segundo plano. A propósito do conto "Luiz da Serra", de Lúcio de Mendonça, Alexandre Eulalio se refere às "descrições iniciais caras aos prosadores do Romantismo - descrições que valiam como uma demonstração de pulso do estilista que geralmente não eram".$^{38}$ Flora Süssekind, investigando o surgimento da prosa de ficção na literatura brasileira da primeira metade do século XIX, observa que o narrador desses textos se constituiu, em parte, num diálogo com o relato de viagem e com as pranchas e desenhos que o acompanhavam. A aproximação a esses interlocutores teria-lhe conferido um olhar "paisagístico-naturalista" capaz de auxiliá-lo na tarefa de

${ }^{35}$ Idem, ibidem.

${ }^{36}$ Idem. O nosso cancioneiro. Ed. cit. p. 969.

${ }^{37}$ Idem. Iracema. Ed. cit. p. 95.

${ }^{38}$ EULAIO, Alexandre. "O Último Bom Selvagem", in Separata da Revista do Livro, Rio de Janeiro, dezembro/1960, no 20, p. 37. 
forjar uma imagem unificada para um país recém-independente e assombrado pelo fantasma da desagregação territorial:

Listam-se árvores, frutas, pássaros e locais pitorescos, tenta-se descrevêlos e nomeá-los cuidadosamente. [...] Minúcia descritiva e olhar de "naturalista" dominantes na formação do narrador dessa primeira prosa de ficção no Brasil. Aí, vistas e detalhes paisagísticos, coqueiros, palmeiras, sabiás, laranjais, pombas ocupam o cenário ficcional, ao mesmo tempo que se tornam objeto de classificação e estudo nos tratados descritivos, diários e relatos de viajantes e expedições

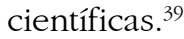

Apesar de haver exemplos desses painéis da natureza em $O$ sertanejo, sua abertura parece afastar-se desse modelo. Nela, ao invés de pintar um quadro, inventariando perspectivas ou espécies animais e vegetais, são apresentados os principais elementos através dos quais o autor caracteriza o sertão. Como numa abertura sinfônica, levantamse temas que serão posteriormente retomados e desenvolvidos ao longo da narrativa: o sertão imenso, o gado e o vaqueiro, a vinculação do espaço sertanejo ao momento privilegiado da infância, a idéia de que no sertão o homem vive em comunhão com a natureza, a noção fundamental de que com o passar do tempo esse vasto território vai sendo domesticado, a percepção das estradas e caminhos como elemento civilizador, a valorização do passado, e, finalmente, sua percepção como lugar do perigo e da aventura.

A imagem do sertão desenvolvida por José de Alencar coadunase com as idéias dos autores anteriormente citados, que o compreendiam como as terras incultas e pouco povoadas do interior do país, ou, na formulação de Antonio de Morais Silva, o "mato longe da costa". Sem fixar limites claros, o ficcionista indica apenas tratar-se de um vasto território ainda não completamente domesticado. Na abertura do romance, ele é descrito como a "imensa campina que se dilata por horizontes infindos", o "vastíssimo deserto", as "remotas regiões", "o espaço

${ }^{39}$ SÜSSEKIND, Flora. O Brasil não é longe daqui, São Paulo, Companhia das Letras, 1990, p. 60.

${ }^{40}$ ALENCAR, José de. O sertanejo. Ed. cit. p.542. 
entre as raras freguesias espalhadas pelo interior da província". Antes de receber o nome de "Quixeramobim", os desbravadores chamavam essas terras de "Campo Maior", tal a sua extensão e grandiosidade. ${ }^{40}$

Ciente de que o caráter movediço da região com a qual trabalhava não lhe permitiria definir contornos precisos, Alencar limitou-se a fixar os grandes horizontes que o delimitavam. A narrativa inicia-se com um grupo de viajantes atravessando uma chapada abrasada pela seca. O fato de o romance abrir-se com uma viagem é revelador do espaço que lhe serve de cenário: o sertão é o distante, o ponto para onde os personagens se dirigem. Assim ocorre em Inocência e $O$ guarani, romances que apresentam entre suas primeiras cenas a chegada de viajantes a algum lugar afastado do interior. Assim ocorre também em O sertanejo, cuja ação inicia-se com a chegada do capitão-mor Gonçalo Pires Campelo e de sua família de uma viagem ao Recife. O capitão-mor costumava fazer essa viagem a cada três anos, e dessa vez levara consigo D. Flor, sua filha, que, nascida no sertão, ainda não conhecia a capital de Pernambuco. De lá, a menina trazia "galanterias de toda sorte, das mais finas e custosas que então se vendiam nas lojas e tendas do Recife". ${ }^{41}$ A cidade é o lugar do movimento, do comércio e da moda, das festas e torneios corteses (como a cavalhada em homenagem à chegada do novo governador, Dom Antonio de Menezes, à qual a família de Campelo assistiu). As cidades populosas formam um dos horizontes do sertão. A fronteira entre esses dois espaços não é assinalada por nenhum traço nítido, pelo contrário, ela é de tal forma imprecisa que o narrador nem sequer se refere a ela. A aproximação do espaço sertanejo só é percebida por alguns sinais subjetivos e indeterminados. Foi o "fogoso cavalo" montado por D. Flor, natural daqueles campos, que a pressentiu antes de todos, mostrandose "excitado desde que primeiro sentira as auras da terra natal". ${ }^{42}$

\footnotetext{
${ }^{41}$ Idem, ibidem. p. 589.

${ }^{42}$ Idem, ibidem. p. 531.
} 
O destino dos viajantes é a fazenda da Oiticica, de propriedade do capitão-mor. O nome da "herdade" era uma homenagem de seu fundador à majestosa árvore que havia em seu terreiro:

$\mathrm{Na}$ frente elevava-se no terreiro, a algumas braças da estrada, a frondosa oiticica, donde viera o nome à fazenda. Era um gigante da antiga mata virgem que outrora cobria aquele sítio.

$\mathrm{Na}$ ocasião da derrubada, sua majestosa beleza moveu o fazendeiro a respeitá-la, destinando-a a ser como que o lar indígena da nova habitação fundada ai nesses ermos. ${ }^{43}$

O narrador situa essa fundação no final do século XVIII, período no qual os "fidalgos de fortuna iam assentando nas terras de conquista" as suas fazendas. ${ }^{44}$

Antes de serem desbravadas, as matas que agora constituíam o sertão de Quixeramobim eram dominadas pela nação dos índios Jucás:

Os primeiros povoadores a tinham expelido dos Inhamuns, onde vivia à margem do rio que ainda conserva seu nome.

Depois de renhidos combates, os Jucás refugiaram-se nos Cratius, de onde refazendo as perdas sofridas e aproveitando a experiência anterior, se lançaram de novo na ribeira do Jaguaribe, assolando as fazendas e povoados. ${ }^{45}$

Na época da infância de Arnaldo, herói da história, os índios ainda ameaçavam o sertão de Quixeramobim, e é num episódio que conta com a participação do pequeno vaqueiro que a paz foi alcançada. Os índios aparecem novamente no final da narrativa, desempenhando importante papel para livrar a Oiticica do cerco a que estava submetida. O seu território, a selva misteriosa, ainda não penetrada pelo homem branco, constitui o outro horizonte do sertão.

\footnotetext{
${ }^{43}$ Idem, ibidem. p. 541. Grifo meu.

${ }^{44}$ Idem, ibidem. Grifo meu.

${ }^{45}$ Idem, ibidem. p. 683.
} 
Neste romance de José de Alencar, o sertão aparece como o espaço compreendido entre as grandes cidades e a floresta desconhecida e ameaçadora. Território de bordas, contém em si elementos dos dois mundos que o confinam: seus moradores e a civilização por eles construída remetem à cidade, e a grandiosa oiticica que se ergue no terreiro da fazenda é um vestígio da antiga floresta que aí existia, conservada para ser o "lar indígena" da nova morada. Para o romancista, os sertões eram as "terras de conquista", território havia pouco tomado à "antiga mata virgem" e aos índios que a dominavam.

Percebê-lo como terra recém-conquistada é não apenas reconhecê-lo como um espaço bélico e perigoso, mas também como território em movimento constante, que se vai embrenhando pelo interior conforme os colonizadores avançam pelo mato, e que, simultaneamente, cede terreno para a cidade que avança em sua direção, domesticando suas terras incultas. "De dia em dia aquelas remotas regiões vão perdendo a primitiva rudeza, que tamanho encanto lhes infundia", ${ }^{46}$ anota o narrador na abertura do romance. Com isso, reforça-se a idéia de que o sertão é uma franja que se imiscui entre as cidades e zonas mais densamente povoadas. Ao reconhecê-lo como uma zona móvel e em perene transformação, o ficcionista eximiu-se da tarefa de erigir pontos geográficos precisos para delimitá-lo, e adotou, em seu lugar, uma espécie de coordenada temporal. Em José de Alencar, o tempo está inscrito no sertão. Por se transformar "de dia em dia", ele se torna um espaço definido por um momento, um instante transitório do processo de desbravamento. O território que ontem foi mato bravio, hoje é sertão e amanhã será terra domesticada. O espaço selvagem constitui o futuro da conquista (o que ainda não foi devassado, para onde o colonizador se dirige) e o passado do conquistado (a lembrança do que existia anteriormente). O sertão é fronteira de conquista, ele assinala uma franja, o ponto de intersecção entre dois tempos e dois mundos.

${ }^{46}$ Idem, ibidem. p. 527. 
Feita essa verificação do que era o espaço sertanejo para José de Alencar e outros escritores coevos, gostaria de ressaltar alguns elementos que orientaram minha leitura desses textos.

Ao discutir o desenvolvimento da prosa de ficção na literatura brasileira do século XIX, Antonio Candido observou que os nossos primeiros romancistas, imbuídos do nacionalismo literário que os levava a descrever lugares e costumes do povo, entregaram-se a um verdadeiro trabalho de mapeamento do país, que ia sendo descoberto e fixado nos seus mais diversos aspectos. "O nosso romance - diz Candido - tem fome de espaço e uma ânsia topográfica de apalpar todo o país. Talvez o seu legado consista menos em tipos, personagens e peripécias do que em certas regiões tornadas literárias [...]. Assim, o que se vai formando e permanecendo na imaginação do leitor é um Brasil colorido e multiforme, que a criação artística sobrepõe à realidade geográfica e social". ${ }^{47}$

O sertão foi uma das regiões tornadas literárias nesse período. A hipótese que orienta minha análise é de o sertão ser, além de uma região geográfica, um espaço ficcional, constituído pelas diversas narrativas que se foram sedimentando umas sobre as outras ao longo do tempo. Nesse sentido, os relatos nele ambientados não se limitam a representar um lugar dado a priori, desempenhando antes papel ativo na construção das suas imagens. O fato de essa região geográfica não possuir contornos naturais visíveis somado à indeterminação do nome "sertão" colaborou para a ficcionalização de um lugar que ninguém sabia exatamente o que era ou onde ficava, mas sobre o qual se contavam histórias fabulosas. Nos romances de Alencar, Taunay e Bernardo Guimarães, esse espaço foi imaginado a partir dos lugares-comuns que compunham a visão

${ }^{47}$ CANDIDO, Antonio. Formação da literatura brasileira. V. 2. Belo Horizonte, Ed. Itatiaia, 1981, p.114.

${ }^{48}$ ALENCAR, Heron. "Sertão". In: Jacinto do Prado Coelho (org.). Dicionário de literatura. Rio de Janeiro, Cia. José Aguilar Ed., 1973. 
romântica da natureza e utilizado como elemento distintivo do Brasil frente à Portugal e aos demais países da Europa.

Por fim, deve-se ressaltar a importância desses textos como fundadores de uma tradição literária que perdura até os nossos dias. Para Heron de Alencar, foi a obra de autores como Bernardo Guimarães, José de Alencar, Franklin Távora e Taunay que "permitiu a conceituação de uma literatura sertanista", ${ }^{48}$ enquanto Cavalcanti Proença, num prefácio que escreveu para A bagaceira, afirmava: "Porque o vento do sertão é a liberdade, o homem sertanejo é o valente, o honrado, o melhor. Há um mito do sertão. Antigo. Está em José de Alencar, em Franklin Távora. Está nos documentos velhos, nos romances populares, cantados em quadra ou sextilha". ${ }^{49}$ Esse mito do sertão constitui um dos principais temas da nossa literatura. Como fundadores da tradição, os escritores românticos estabeleceram uma série de lugares-comuns que seriam posteriormente retomados e transformados, numa linha que tem seus pontos nodais nas obras de Euclides da Cunha, dos ficcionistas nordestinos da década de 1930 e de João Guimarães Rosa, e que se prolonga até hoje com Francisco Dantas.

${ }^{49}$ PROENÇA, M. Cavalcanti. "A Bagaceira”. In: Estudos literários. Rio de Janeiro, José Olympio Ed./INL, 1974. p.398. 


\section{Resumo}

O objetivo desse artigo é analisar o significado que a palavra "sertão" assume em alguns textos produzidos no século XIX em especial no romance O sertanejo, de José de Alencar. Partindo do pressuposto de o sertão ser, além de uma região geográfica, um espaço ficcional constituído pelas diversas narrativas que foram forjando suas imagens ao longo do tempo, procuro determinar como dicionaristas, viajantes e romancistas compreenderam esse termo e caracterizaram esse espaço em seus textos.

\section{Abstract}

This paper aims to analyze the meaning of the word "sertão" (usually translated as "the backland") in some texts written in the nineteenth-century - specially in "O sertanejo", a novel by José de Alencar. Beginning with the theory that the "sertão" is an imaginary place in literature created over time by various narratives, I have tried to identify how some lexicographers, travellers and novelists understood this word and depicted this space in theirs works. 